\title{
SO SÁNH HIẾU QUẢ LÀM SẠCH CỦA HAI HỆ THỐNG DỤNG CỤ ĐƠ'N TRÂM
}

\section{TÓM TẮT}

Mục tiêu: So sánh hiệu quả làm sạch của hai hệ thống dụng cụ đơn trâm tương đối mới hiện nay. Phương pháp: 40 răng cối nhỏ hàm dưới của người đã nhổ được chia đều cho hai nhóm $(n=20)$ : nhóm WOG sửa soạn với hệ thống trâm quay qua lại, nhóm SAF sửa soạn với hệ thống trâm dao động. Các răng sau sửa soạn được tách đôi theo chiêu dọc thành hai phân để khảo sát hiệu quả làm sạch bằng kính hiển vi điện tử quét ở các vị trí $2 \mathrm{~mm}, 5 \mathrm{~mm}$ và $8 \mathrm{~mm}$ cách chóp tương ứng với phần ba chóp, cổ và giữa thông qua điểm số mảnh vụn và lớp mùn bởi hai quan sát viên độc lập. Kết quả: Có sự khác biệt có ý nghĩa thống kê về điểm số mảnh vưn toàn bộ $(p=0,028)$ và ở phân ba giữa $(p=0,04)$, điểm số lớp mùn ở phần ba chóp $(p=0,014)$ giữa hai nhóm. Kết luận: Hệ thống đơn trâm dao động có hiệu quả làm sạch mảnh vụn toàn bộ, ở phân ba giữa và hiệu quả làm sạch lớp mùn ở phân ba chóp tốt hơn so hệ thống trâm quay qua lại.

Tư khóa: Hiệu quả làm sạch, hệ thống đơn trầm quay qua lại, hệ thống đơn trâm dao động, nội nha.

\section{SUMMARY \\ COMPARISON OF THE CLEANING EFFICACY OF TWO SINGLE FILE SYSTEMS}

Objectives: To compare the cleaning efficacy of two novel single file systems. Methods: Forty freshly extracted mandibular premolars were equally divided into two groups: WOG group prepared by WaveOne Gold file, SAF group prepared by Self-adjusting file. These teeth were sectioned longitudinally and processed for evaluation of debris and smear layer score under Scanning Electronic Microscope at $2 \mathrm{~mm}$, $5 \mathrm{~mm}$ and $8 \mathrm{~mm}$ from the apex by two observers. Results: There were statistically significant differences between two groups in debris score (overall, middle third) and smear layer score (apical third) $(p<0,05)$. Conclusion: The self-adjusting file system is more efficacious than WaveOne Gold system in terms of cleaning debris (overall and middle third) and smear layer (apical third).

Keywords: Cleaning efficacy, WaveOne Gold file, Self-adjusting file, endodontic treatment

\section{I. ĐĂ̆T VẤN ĐỀ}

Với mong muốn bảo tồn cấu trúc răng tự nhiên về cả mặt chức năng cũng như thẩm mỹ,

\footnotetext{
${ }^{1}$ Khoa Răng Hàm Mặt, Trường ĐH Trà Vinh.

${ }^{2}$ Khoa Răng Hàm Mặt, ĐH Y Dượ TP.HCM. Chịu trách nhiệm chính: Nguyễn Phúc Nguyên Email: npnguyen@tvu.edu.vn Ngày nhận bài: 26/9/2021

Ngày phản biện khoa học: 20/10/2021

Ngày duyệt bài: 3/11/2021
}

nội nha được thực hiện nhằm ngăn ngừa và điêu trị sự nhiễm khuẩn bên trong ống tủy và/hoặc mô vùng quanh chóp. Để đáp ứng mục tiêu đó, có sự đa dạng của phương pháp và dụng cụ dùng trong điều trị nội nha nhưng nhìn chung chúng đều có mục tiêu cơ học giống nhau là làm sạch và tạo dạng hệ thống ống tủy [1].

Bằng kính hiển vi điện tử quét, sự hiện diện của mảnh vụn và lớp mùn đã lần đầu được Eick xác nhận năm 1970. Từ những năm 1975 nghiên cứu của McComb và Smith đã mô tả đặc điểm của lớp mùn trên bề mặt ống tủy sau khi có tác động của dụng cụ sửa soạn ống tủy [1]. Mặc dù có sự tranh cãi về việc giữ lại hay loại bỏ lớp mùn, tuy nhiên thực tểló́p này đóng vai trò quan trọng trong việc tạo thành vi kẽ, ảnh hướng đến sự kín khít khi trám bít ống tủy, lớp này cũng làm giảm hiệu quả kháng khuẩn của các thuốc đặt trong ống tủy vì vậy xu hướng loại bỏ lớp mùn ngày càng chiếm ưu thế [8].

Việc sử dụng hợp kim NiTi trong thiết kế dụng cụ góp phần cải thiện tính hiệu quả, chất lượng trong quá trình tạo dạng ống tủy và ngăn ngừa sai lầm trong lúc sửa soạn nội nha, ngoài ra còn nhằm mục đích làm đơn giản hóa thao tác, giảm số lượng dụng cụ phải sử dụng, song song với việc bảo tồn hình dạng nguyên thủy của hệ thống ống tủy[1]. Bằng cách giữ lại các đặc điểm cấu tạo cốt lõi của dụng cụ thép không rỉ trong quá khứ và kết hợp với sự thay đổi về công nghệ luyện kim, độ thuôn, thiết kế cắt ngang và kiểu vận động, các hệ thống dụng cụ đơn trâm lần lượt ra đời[6]. Trong đó hai hệ thống dụng cụ đởn trâm quay qua lại và dao động là hai hể thống tương đối mới hiện nay, vẫn còn hạn chể các nghiên cứu để đánh giá hiệu quả làm sạch của chúng.

Vì vậy chúng tôi tiến hành nghiên cứu in vitro này với mục tiêu là đánh giá hiệu quả làm sạch của hai hệ thống dụng cụ đơn trâm dao động và quay qua lại thông qua khảo sát bằng SEM với thang đo điểm số mảnh vụn và lớp mùn.

\section{II. ĐỐI TƯỢNG VÀ PHƯƠNG PHÁP NGHIÊN CỨU}

2.1. Đối tượng nghiên cứu. Răng cối nhỏ hàm dưới của người đã nhổ vì lý do chỉnh nha.

Tiêu chuẩn chọn vào. Chân răng còn nguyên vẹn chưa được điều trị tủy, ống tủy không bị vôi hóa, răng đã đóng chóp, lỗ chóp 
cho trâm K-file số 10 đi qua, ống tủy cong từ 0 đến 20 độ theo phương pháp đo độ cong của Schneider.

Tiêu chuẩn loại ra. Lỗ chóp ống tủy cho trâm K-file lớn hơn 15 đi qua, ống tủy bị nội tiêu.

2.2. Cỡ mẫu nghiên cứu. Cỡ mầu được tính bằng phần mềm G*power (G*power 3.1.9, Heinrich-Heine-Universität Düsseldorf, Đức) với các giá trị: $a=0,05$, power $=0,95$. Dựa trên kết quả từ nghiên cứu của Ozsu (2014)[6] chúng tôi tính được hê số ảnh hưởng (effect size) cho nghiên cứu là: 1.197342. Sau khi nhâp liệu vào phần mềm kết quả cho thấy cần tối thiểu 16 răng cho mỗi nhóm để đảm bảo có thể quan sát được sự khác biệt giữa các nhóm. Nhằm tăng sức mạnh thống kê chúng tôi chọn 20 răng cho mỗi nhóm. Như vậy tổng số răng cần cho nghiên cứu là 40, trong đó 20 răng cho nhóm WOG, 20 răng cho nhóm SAF.

\subsection{Phương pháp nghiên cứu}

Thiết kế nghiên cứu. Nghiên cứu thử nghiệm in vitro.

Sửa soạn mẫu nghiên cứu. Các răng sau khi nhổ được sát khuẩn bằng dung dịch Thymol $0,1 \%$, làm sạch mô mềm quanh răng và ngâm trong dung dịch $\mathrm{NaCl} 0,9 \%$ chờ đến khi đủ mầu.

Mở lối vào ống tủy: tất cả các răng được mở tủy bằng mũi khoan kim cương tròn.

Xác định chiều dài làm việc: đưa trâm K-file số 10 vào ống tủy cho đến khi thây đầu trâm tại lỗ chóp, rút nhe trâm cho đến khi nó vừa lộ ra ở lỗ chóp. Đẩy nút chặn cao su tiếp xúc với phần cao nhất của thân răng, rút trâm ra khỏi ống tủy và đo chiều dài này. Chiều dài làm việc là chiều dài đo được trừ đi $1 \mathrm{~mm}$.

Xác định độ cong của ống tủy: Đă̆t trâm K-file số 10 vào ống tủy, sau đó chụp phim x-quang. Sau khi chụp phim, quét phim vào máy vi tính, sử dụng phần mêm Image] (ImageJ 1.53e, National Institutes of Health, USA) để đo độ cong theo phương pháp Schneider (1971). Ghi nhận độ cong cho từng răng.

Mã hóa và phân nhóm: các răng đáp ứng tiêu chuẩn chọn vào được tập hợp, mã hóa và chia ngẫu nhiển cho 2 nhóm bằng thuật toán phân phối ngẫu nhiên (https://random.org).

Sửa soạn tạo đường trượt. Trước khi thực hiện sửa soạn bằng các hệ thống dụng cụ đợn trẩm, các răng được sửa soạn tạo đường trượt: nhóm WOG sửa soạn tạo đường trượt bằng trâm máy quay qua lại tạo đường trượt, nhóm SAF sửa soạn tạo đường trượt bằng trâm K-file đến số 20.

\section{Sửa soạn chính}

- Nhóm WOG: Trên máy nội nha dùng cho trâm quay qua lại đặt chế độ WaveOne All đưa trâm của hệ thống dụng cụ đơn trâm quay qua lại cỡ 35 độ thuôn $6 \%$ chiều dài $25 \mathrm{~mm}$ vào ống tủy với động tác lên xuống nhe nhàng để đầu trâm trượt thụ động dọc theo ổng tủy, mỗi lần đẩy trâm di chuyển 2-3 mm cho đến khi đủ chiều dài làm việc. Sau mỗi lần sử dụng dụng cụ, lau sạch các rã̃nh trâm bằng gạc ẩm sạch. Bợm rửa sau mỗi lần thay dụng cụ với dung dich $\mathrm{NaOCl}$ $3 \%$, bằng kim bơm rửa nội nha hai lố mở bên, đưa kim đã được đánh dấu mốc ngắn hơn chiêu dài làm viêc $1 \mathrm{~mm}$ vào ống tủy, nếu chưa đạt mốc mà có cảm giác chặt thì rút ngược kim lại $1 \mathrm{~mm}$, bơm với áp lực trung bình, đảm bảo tổng dung tích bơm rửa là $16 \mathrm{ml}$, tốc độ bơm rửa trung bình $4 \mathrm{ml} /$ phút. Sau mối lần bơm rửa kiểm tra lại đường trượt và sự thông suốt của ống tủy bằng cách đưa trâm $\mathrm{K}$ số 10 đến vượt quá chiều dài làm việc $1,5 \mathrm{~mm}$. Sau cùng thấm khô ống tủy bằng côn giấy.

- Nhóm SAF: Trước khi bắt đầu sửa soạn, trâm của hê thống dao động được đặt môt cách thụ động vào đến chiều dài làm việc, nểu trâm không đạt chiều dài làm việc thì thực hiện sửa soạn tạo đường trượt lại và kiểm tra. Trên máy nội nha dùng cho trâm dao động, sử dụng trâm của hệ thống dụng cụ đớn trâm dao động cõ̃ 1.5 $\mathrm{mm}$ chiêu dài $25 \mathrm{~mm}$, động tác dũa theo chiều dọc vào và ra, tần số dao động 5000 lần/phút, biên độ dao động $0,4 \mathrm{~mm}$. Động tác đầy nhe trâm vào ống tủy đến khi đạt chiều dài làm việc, nếu thấy trâm bị cản lại khi chưa tới chiều dài làm việc, hoặc không đạt chiều dài làm việc trong 1 phút đầu sử dụng thì lấy trâm ra và tạo lại đường trượt, tổng thời gian sửa soạn là 4

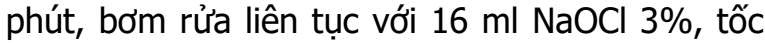
độ bơm rửa $4 \mathrm{ml} /$ phút. Sau cùng thấm khô ống tủy bằng côn giấy.

Chuẩn bị mầu, chụp vi ảnh. Cắt dọc theo chiều ngoài trong của răng, đường cắt không xâm phạm vào ống tủy chân răng. Tác đôi chân răng, chọn ngẫu nhiên một trong hai mảnh, ngâm mấu trong cồn lần lượt có nồng độ $50 \%$, $70 \%, 90 \%$ và $99,97 \%$ trong 20 phút để khử nước.

Chụp vi ảnh với SEM bằng chế độ không phủ tại vị trí $1 / 3$ chóp, $1 / 3$ giữa và $1 / 3$ cổ, tương đương với vị trí $2 \mathrm{~mm}, 5 \mathrm{~mm}$ và $8 \mathrm{~mm}$ từ chóp, độ phóng đại 200 và 1000 lần tương ứng với việc quan sát mảnh vụn và lớp mùn.

Ghi nhânn kết quả. Hai quan sát viên độc lập sẽ ghi nhận điểm số mảnh vụn và lớp mùn dựa trên thang đo của Parente (2010)[7]đã được hiệu chỉnh với các tiêu chí của Çapar (2014) [2]như sau: 
- Chỉ số mảnh vụn ở độ phóng đại 200 lần bằng thang đo gồm 5 điểm:

+ Một điểm: hoàn toàn sạch hoặc chỉ có mảnh vụn bao phủ $\leq 5 \%$ bề mặt.

+ Hai điểm: mảnh vụn bao phủ $>5-\leq 35 \%$ bề mặt.

+ Ba điểm: mảnh vụn bao phủ > $35-\leq$ $65 \%$ bề mặt.

+ Bốn điểm: mảnh vụn bao phủ > $65-\leq$ $95 \%$ bề mặt.

+ Năm điểm: mảnh vụn bao phủ > 95\% bề mặt.

- Chỉ số lớp mùn ở độ phóng đại 1000 lần với thang đo gồm 5 điểm:

+ Một điểm: Không có lớp mùn hoặc bao phủ $\leq 5 \%$ bề mặt, các ống ngà mở.

+ Hai điểm: Lớp mùn hiện diện rõ từ > 5\% đến $\leq 35 \%$ bề mặt, các miệng ổng ngà có thể giảm kích thước, bị bao phủ một phần hay toàn bộ bởi vụn ngà.

+ Ba điểm: Lớp mùn hiên diện rõ từ > 35\% đến $\leq 65 \%$ bề mặt, các miệng ống ngà có thể giảm kích thước, bị bao phủ một phần hay toàn bộ bởi vụn ngà.
+ Bốn điểm: Lớp mùn hiện diện rõ từ > 65\% đến $\leq 95 \%$ bề mặt, các miệng ống ngà có thể giảm kích thước, bị bao phủ một phần hay toàn bộ bởi vưn ngà.

+ Năm điểm: Lớp mùn bao phủ từ > $95 \%$ đến $\leq 100 \%$ bề mặt.

2.4. Xử lý kêt quả. Số liệu được xử lý bằng phần mềmExel và SPSS.

Sử dụng phép kiểm Kappa để đánh giá mức độ kiên định và đồng thuận của hai quan sát viên.

Vì số liệu ghi nhận không có phân phối chuẩn (phép kiểm Shapiro Wilk có $\mathrm{p}<0,05$ ) nên sử dụng phép kiểm Mann-Whitney để tìm kiếm sự khác biệt về điểm số mảnh vụn và lớp mùn nếu có giữa hai nhóm.

\section{KẾT QUẢ NGHIÊN CứU}

Sau hai lần chấm điểm vi ảnh, kết quả được tổng hợp để tính toán trọng số Kappa (Bảng 1), ở những vi ảnh có điểm số giữa hai quan sát viên khác nhau, hai quan sát viên sẽ được yêu cầu ngồi lại cùng đánh giá để đi đến kết quả sau cùng, kết quả này sẽ được dùng để khảo sát sự khác nhau giữa hai nhóm.

Bảng 1. Trọng số Kappa

\begin{tabular}{|c|c|c|c|c|}
\hline STT & \multicolumn{2}{|r|}{ Đánh giá } & Trọng số Kappa & Xếp loai \\
\hline 1 & \multirow{3}{*}{$\begin{array}{c}\text { Điểm số } \\
\text { mảnh vụn }\end{array}$} & Độ kiên định quan sát viên 1 & 0,91 & Rầt cao \\
\hline 2 & & Độ kiên định quan sát viên 2 & 0,89 & Rất cao \\
\hline 3 & & Mức độ đồng thuận 2 quan sát viên & 0,91 & Rất cao \\
\hline 4 & \multirow{3}{*}{$\begin{array}{l}\text { Điểm số } \\
\text { lớp mùn }\end{array}$} & Độ kiên định quan sát viên 1 & 0,89 & Rất cao \\
\hline 5 & & Độ kiên định quan sát viên 2 & 0,86 & Rất cao \\
\hline 6 & & Mức độ đồng thuận 2 quan sát viên & 0,86 & Rất cao \\
\hline
\end{tabular}

Nhóm WOG có điểm số mảnh vụn trung bình ở tất cả vị trí và toàn bộ cao hơn so với nhóm SAF. Phép kiểm Mann-Whitney cho thây sự khác biệt có ý nghĩa giữa hai nhóm về điểm số mảnh vụn toàn bộ $(p=0,028<0,05)$ và vị trí phần ba giữa $(p=0,004<0,05)$ (Bảng 2$)$.

Bảng 2. So sánh điểm số mảnh vụn (Trung bình \pm Độ lệch chuẩn) giữa hai hệ thống

\begin{tabular}{|c|c|c|c|c|}
\hline Nhóm/Vị trí & Chóp & Giữa & Cổ & Toàn bộ \\
\hline WOG & $2,85 \pm 0,88$ & $2,65 \pm 0,67$ & $2,30 \pm 0,66$ & $2,60 \pm 0.58$ \\
\hline SAF & $2,45 \pm 0,69$ & $1,95 \pm 0,51$ & $2,15 \pm 0,75$ & $2,18 \pm 0,52$ \\
\hline p & 0,183 & $0,04^{*}$ & 0,547 & $0,028^{*}$ \\
\hline
\end{tabular}

Phép kiểm Mann-Whitney *Khác biệt có ý nghĩa thống kê $(p<0,05)$

Nhóm WOG có điểm số lớp mùn trung bình ở tất cả vị trí và toàn bộ cao hơn so với nhóm SAF. Phép kiểm Mann-Whitney cho thấy sự khác biệt có ý nghĩa thống kê giữa hai nhóm về điểm số lớp mùn ở vị trí phần ba chóp $(p=0,014<0,05)$ (Bảng 3$)$.

Bảng 3. So sánh điêm số lớp mùn (Trung binh \pm Độ lệch chuẩn) giữa hai hệ thống

\begin{tabular}{|c|c|c|c|c|}
\hline Nhóm/Vị trí & Chóp & Giữa & Cố & Toàn bộ \\
\hline WOG & $5,00 \pm 0,00$ & $4,50 \pm 0,76$ & $4,20 \pm 0,83$ & $4,57 \pm 0,42$ \\
\hline SAF & $4,45 \pm 0,69$ & $4,05 \pm 0,83$ & $3,90 \pm 0,91$ & $4,13 \pm 0,71$ \\
\hline P & $0,014^{*}$ & 0,096 & 0,341 & 0,06 \\
\hline
\end{tabular}

Phép kiểm Mann-Whitney *Khác biệt có ý nghĩa thống kê $(\mathrm{p}<0,05)$

\section{BÀN LUÂN}

Đối với các nghiên cứu về hiệu quả làm sạch, có ba phương pháp chính để khảo sát gồm sinh thiết mô học, khảo sát bằng $\mathrm{SEM}$ và khảo sát bằng Micro-CT. Các nghiên cứu mô học được thực hiện bằng cách cắt lát các răng sau sửa 
soạn, nhuộm và quan sát dưới kính hiển vi, sau đó nhà nghiên cứu sẽ xác định vùng tủy và vụn ngà còn sót lại và/hoặc vùng chưa được sửa soạn để đánh giá hiệu quả làm sạch. Nghiên cứu hiệu quả làm sạch bằng Micro-CT là một hướng đi mới hiện nay, bằng việc quét các răng trước, trong và sau quá trình sửa soạn để tính ra khối lượng vụn ngà tạo thành, được làm sạch và còn sót lại để đánh giá hiệu quả làm sạch. Tuy nhiên, phương pháp phổ biến hơn hết trong khảo sát hiệu quả làm sạch là sử dụng SEM để khảo sát các răng sau sửa soạn thông qua điểm số mảnh vụn và lớp mùn bởi vì tính sẵn có của thiết bị và kinh tế hơn so với Micro-CT[8].

Thang đo mảnh vụn và lớp mùn gồm năm điểm của Hulsmann và của Parente được nhiều nghiên cứu sử dụng. Thang đo của Hulsmann ra đời năm 1997 với hệ thống điểm chú trọng về tính định tính bởi quan sát viên[7]. Thang đo của Parente ra đời năm 2010 bao gồm cả đánh giá định tính và một phần định lượng đặc điểm của mảnh vụn, lớp mùn giúp giảm đi sự cảm tính của quan sát viên. Nghiên cứu của chúng tôi dựa trên thang đo của Parente kết hợp với sự hiệu chỉnh giá trị định lượng theo nghiên cứu của Çapar[2]để chi tiết hóa các mức điểm số hạn chế tối đa sự cảm tính trong đánh giá. Ở nghiển cứu của chúng tôi vi ảnh được đặt một lưới gồm 100 ô bằng nhau giúp quan sát viên thuận tiện trong việc tính toán diện tích lớp mùn ngà bao phủ (Hình 1).

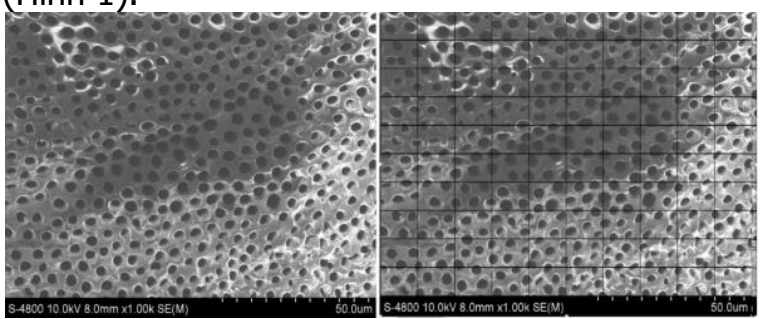

Hình 1. Vi ảnh trước và sau khi được thêm lưới đánh giá

Việc đánh giá điểm số mảnh vụn và lớp mùn bằng thang đo cũng có nguy cơ sai lệch do đo lường. Để khắc phụ những yếu tố này, ở nghiên cứu của chúng tôi việc chụp vi ảnh thực hiện hoàn toàn khách quan bởi nhân viên phòng thí nghiệm có nghiệp vụ chụp SEM, người này được hướng dẫn để xác định vị trí trung tâm của ống tủy tại các mốc $2 \mathrm{~mm}, 5 \mathrm{~mm}$ và $8 \mathrm{~mm}$, chụp vi ảnh hoàn toàn ngẫu nhiên, người này không có chuyên môn về nội nha nên có thể xem các vi ảnh gần như ngẫu nhiên hoàn toàn. Đối với việc đánh giá điểm số, hai quan sát viên độc lập tiển hành đánh giá riêng biệt, thông qua giá trị trọng số Kappa cho thấy hai quan sát viên có mức độ kiên định và mức độ đồng thuận rất cao.

Trong nghiên cứu của chúng tôi điểm số trung bình mảnh vụn và lớp mùn của nhóm WOG ở tất cả vị trí và toàn bộ đều cao hơn so với nhóm SAF, trong đó có sự khác biệt có ý nghĩa thống kê $(p<0,05)$ về điểm số mảnh vụn toàn bộ và ở vị trí phần ba giữa, cũng như điểm số lớp mùn ở vị trí phần ba chóp giữa hai nhóm. Đến thời điểm hiện tại chưa có nghiên cứu nào so sánh điểm số mảnh vụn và lớp mùn giữa hai nhóm trong cùng một điều kiện.

Nghiên cứu của Ismail (2019) [3] cho thấy điểm số mảnh vụn toàn bộ của nhóm WOG là 1,84 điểm cao hớn nhóm dụng cụ quay liên tục (nhóm PTN) ở mức 1,77 điểm. Trong nghiên cứu của chúng tôi điểm số mảnh vụn của nhóm WOG là 2,06 điểm. Nghiên cứu của Jadhav(2016) [4] so sánh điểm số mảnh vụn ở vị trí phần ba chóp giữa nhóm $\mathrm{PTN}$ và $\mathrm{SAF}$ tác giả báo cáo rằng nhóm SAF có điểm số mảnh vụn (1,55 điểm) thấp hơn có ý nghĩa thống kê so với PTN $(2,2$ điểm). Điểm số mảnh vụn giữa nghiên cứu của chúng tôi và các tác giả này có sự khác nhau có thể nguyên nhân từ việc loại răng sử dụng, kích cõ̃ dụng cụ, loại dung dịch bơm rửa khác nhau.

Trong nghiển cứu của Ismail (2019)[3], khi so sánh điểm số lớp mùn toàn bộ và ở ba vị trí giữa nhóm WOG và PTN cho thây kết quả điểm số lớp mùn giữa hai nhóm là tương đồng nhau. Trong nghiên cứu của Jadhav (2016) [4], khi so sánh điểm số lớp mùn ở vị trí phần ba chóp thì nhóm PTN $(2,5 \pm 0,76)$ cao hơn có ý nghĩa thống kê so nhóm SAF $(1,85 \pm 0,74)$. SAF với thiết kế không có lõi kim loại trung tâm mà thay vào đólà một lưới rỗng mắt cáo với bề mặt được làm nhám, kết hợp với kiểu vận động trâm dao động ở tần số cao có tác dụng như một thiết bị "kích hoạt" dung dịch bơm rửa, giúp cho dòng bơm rửa của ống tủy được làm mới một cách hiệu quả, tác dụng này kéo dài liên tục trong suốt quá trình sửa soạn giúp đạt được hiệu quả làm sạch tốt hơn[5]. Nhóm WOG và PTN được bơm rửa với kim bơm rửa truyền thống nên không có tác dụng kích hoạt dung dịch bơm rửa, điều này có thể dẫn đến điểm số mảnh vụn, lớp mùn của nhóm SAF có phần tốt hơn so với hai nhóm này.

\section{KẾT LUẬN}

Hệ thống đơn trâm dao động có hiệu quả làm sạch mảnh vụn (toàn bộ và phần ba giữa) và lớp mùn (phần ba chóp) tốt hơn so với hệ thống đơn trâm quay qua lại. Tuy nhiên cả hai hệ thống không có hiệu quả làm sạch hoàn toàn mảnh 
vụn và lớp mùn vì vậy cân kết hợp thêm các biện pháp khác để có kết quả tốt hơn.

\section{TÀI LIÊU THAM KHẢO}

1. Berman L. H., Hargreaves K. M. (2020), Cohen's Pathways of the Pulp- 12th Edition, Elsevier Health Sciences, tr 855-1064.

2. Çapar ì. D., Ari Aydinbelge H. (2014), "Effectiveness of various irrigation activation protocols and the self-adjusting file system on smear layer and debris removal", Scanning: The Journal of Scanning Microscopies, 36 (6),640-647.

3. Ismail A. G., Nagy M. M., Galal M. (2019), "Cleaning ability of rotary NiTi systems with different kinematics", Bulletin of the National Research Centre, 43 (1), 1-5.

4. Jadhav G. R., Mittal P., Kulkarni A. et al. (2016), "Comparative evaluation of canal cleaning ability of various rotary endodontic filesin apical third: A scanning electron microscopic study", Dental research journal, 13 (6),508.
5. Metzger Z., Teperovich E., Cohen R. et al. (2010), "The self-adjusting file (SAF). Part 3: removal of debris and smear layer-a scanning electron microscope study", Journal of endodontics, 36 (4),697-702.

6. Ozsu D., Karatas E., Arslan H. et al. (2014), "Quantitative evaluation of apically extruded debris during root canal instrumentation with ProTaper Universal, ProTaper Next, WaveOne, and selfadjusting file systems", European journal of dentistry, 8 (4), 504-508.

7. Parente J., Loushine R., Susin L. et al. (2010), "Root canal debridement using manual dynamic agitation or the EndoVac for final irrigation in a closed system and an open system", International Endodontic Journal, 43 (11),1001-1012.

8. Plotino G., Özyürek T., Grande N. M. et al. (2019), "Influence of size and taper of basic root canal preparation on root canal cleanliness: a scanning electron microscopy study", International Endodontic Journal, 52 (3),343-351.

\section{ĐÁNH GIÁ ẢNH HƯởNG LÊN HUYẾT ÁP CỦA CAO CHIẾT HẠT CÀ PHÊ XANH VIỆT NAM TRÊN ĐộNG VẬT THỰC NGHIỆM}

\section{TÓM TẮT}

Mục tiêu: Đánh giá tác dụng của cao chiết hạt cà phê xanh Việt Nam lên các loại huyết áp thành phân trên động vật thực nghiệm. Đối tượng và phương pháp: 40 chuột nhắt trắng chủng Swiss được chia thành 4 nhóm nghiên cứu: nhóm 1 (nhóm chứng) chuột được uống nước muối sinh lý với thể tích $0,1 \mathrm{ml} / 10$; nhóm 2, nhóm 3 và nhóm 4 (các nhóm điều trị) - chuột được uống cao chiết hạt cà phê xanh với các liêu $200 \mathrm{mg} / \mathrm{kg}, 300 \mathrm{mg} / \mathrm{kg}$ và $400 \mathrm{mg} / \mathrm{kg}$ cho mỗi nhóm. Chuột được uống nước muối sinh lý hoăc cao chiết hat cà phê xanh hàng ngày trong 3 tuânn liển tiếp. Sau đó, chuột được cho thực hiện bài tập chạy gắng sức trến hệ thống treadmill. Đánh giá huyết áp đuôi chuột trước và sau gắng sức 1 phút, 3 phút và 5 phút. Kết quả: Chuột uống cao chiết hạt cà phê xanh liều $400 \mathrm{mg} / \mathrm{kg}$ và một phần liều $300 \mathrm{mg} / \mathrm{kg}$ làm giảm huyết áp tâm thu, huyết áp tâm trương, huyết áp hiệu số và huyết áp trung bình khi gắng sức so với uống nước muối trên động vật thực nghiệm. Kết luận: cao chiết hạt cà phê xanh có tác dụng làm ổn định huyết áp, tránh sự tăng huyết áp quá cao khi gắng sức.

\footnotetext{
${ }^{1}$ Hoc Viên Quân y

²Bệnh viện TUQQD 108

${ }^{3}$ Ban Quân y, Bộ Tham mưu, QK 4.

Chịu trách nhiệm chính: Lê Văn Quân

Email: levanquan2002@gmail.com

Ngày nhận bài: 15/9/2021

Ngày phản biện khoa học: 5/10/2021

Ngày duyệt bài: 1/11/2021
}

\author{
Lê Văn Quân', Cấn Văn Mão ${ }^{1}$, \\ Nguyễn Trọng Nghĩa ${ }^{2}$, Nguyễn Văn Thuần ${ }^{3}$ \\ Tư khóa: Huyết áp, cao chiết hạt cà phê xanh, \\ chuột nhắt.

\section{SUMMARY \\ EFFECTS OF VIETNAM GREEN COFFEE EXPERIMENTAL ANIMALS} \\ BEAN EXTRACT TO BLOOD PRESSURES IN
}

Objective: To assess effects of Vietnam gree coffee bean extract to blood pressures in experimental animals. Subjects and methods: 40 Swiss mice were divided randomly into 4 groups: group 1 (control) - animals were administrated vehicle at $0,1 \mathrm{ml} / 10 \mathrm{~g}$; groups 2, 3 and 4 (treatments) - animals were contributed green coffee bean extracts at doses $200 \mathrm{mg} / \mathrm{kg}, 300 \mathrm{mg} / \mathrm{kg}$ and $400 \mathrm{mg} / \mathrm{kg}$, respectively. Animals were contributed vehicle or green coffee bean extracts daily for 3 continous weeks. After then, animals were perfomed running tests in the treadmill system. Blood presures of all animals were measured before and after the test 1 minute, 3 minutes, 5 minutes. Results: All kinds of blood pressures in animals treated green coffee bean extracts at doses $400 \mathrm{mg} / \mathrm{kg}$ and $300 \mathrm{mg} / \mathrm{kg}$ were lower than these in control animals after the behavioral test. Conclusion: Vietnam green coffee bean extract induced stability of blood presures in experimental animals.

Keywords: Blood pressures, Vietnam gree coffee bean extract, mice

\section{I. ĐặT VẤN ĐỀ}

Cao chiết hạt cà phê xanh được chứng minh có nhiều tác dụng có lợi đối với sức khỏe con 